\title{
Effects of Food Types, Frying Frequency, and Frying Temperature on 3-Monochloropropane-1,2-diol Esters and Glycidyl Esters Content in Palm Oil during Frying
}

\author{
Jinglin Zhang 1,2,3®, Wendi Zhang ${ }^{2,3}$, Yuanzheng Zhang ${ }^{2,3}$, Mingquan Huang ${ }^{2,3, *}$ and Baoguo Sun ${ }^{2,3}$ \\ 1 College of Food Science and Engineering, Tianjin University of Science \& Technology, Tianjin 300457, China; \\ zhanginglin@btbu.edu.cn \\ 2 Key Laboratory of Brewing Molecular Engineering of China Light Industry, Beijing Technology \& Business \\ University (BTBU), Beijing 100048, China; 2030302049@st.btbu.edu.cn (W.Z.); 2128003403@btbu.edu.cn (Y.Z.); \\ sunbg@btbu.edu.cn (B.S.) \\ 3 Beijing Key Laboratory of Flavor Chemistry, Beijing Technology \& Business University (BTBU), \\ Beijing 100048, China \\ * Correspondence: huangmq@th.btbu.edu.cn
}

check for updates

Citation: Zhang, J.; Zhang, W.; Zhang, Y.; Huang, M.; Sun, B. Effects of Food Types, Frying Frequency, and Frying Temperature on

3-Monochloropropane-1,2-diol Esters and Glycidyl Esters Content in Palm Oil during Frying. Foods 2021, 10 , 2266. https://doi.org/10.3390/ foods10102266

Academic Editor: Maria D. Guillen

Received: 27 August 2021

Accepted: 19 September 2021

Published: 24 September 2021

Publisher's Note: MDPI stays neutral with regard to jurisdictional claims in published maps and institutional affiliations.

Copyright: (c) 2021 by the authors. Licensee MDPI, Basel, Switzerland. This article is an open access article distributed under the terms and conditions of the Creative Commons Attribution (CC BY) license (https:/ / creativecommons.org/licenses/by/ $4.0 /)$.

\begin{abstract}
Monochloropropanediol esters (3-MCPDE) and glycidyl esters (GE) have high toxicity and have drawn global attention because of their widespread occurrence in refined oils and oil-based foods. In this study, the effects of food type (potato chips and chicken breasts), frying frequency, and frying temperature on the formation of 3-MCPDE and GE in palm oil (PO) were investigated. The results showed that 3-MCPDE was formed easier in chicken breasts than potato chips. The GE content decreased in PO after it was used for frying potato chips and chicken breasts with or without $\mathrm{NaCl}$. Frying frequency was an influencing factor in the formation of 3-MCPDE and the decrease in GE in PO. Frying temperature was positively correlated with GE degradation, while it had a bidirectional effect on the formation of 3-MCPDE. The formation kinetic equations indicated that 3-MCPDE and GE followed zero-order reactions in PO. The estimated activation energy (Ea) of 1,2-bis-palmitoyl-3-chloropropanediol (Pa-Pa, $41.05 \mathrm{~kJ} / \mathrm{mol}$ ) was lower than those of the other three types of 3-MCPDE; this is the first theoretical explanation for why PO contains more 3-MCPD than other edible oils. Among GEs, glycidyl oleate (Li-GE) was degraded more readily than other GEs.
\end{abstract}

Keywords: palm oil; kinetic; frying model; influence factors; 3-MCPDE; GE

\section{Introduction}

Elucidating the formation of 3-monochloro-1,2-propanediol esters (3-MCPDE) and glycidyl esters (GE) during heat processing of frying foods is vital for reducing risks to human health. Although the toxicology of 3-MCPDE and GE has rarely been investigated, the free forms of 3-MCPD and glycidol have been classified as group 2B (possible human carcinogens) and group 2A (probably carcinogenic to humans) carcinogens by the International Agency for Research on Cancer (IARC), respectively [1]. In addition, recent scientific studies have indicated that 3-MCPD and glycidyl are present in the human digestive tract [2]. In fact, a large part of the MCPD in foods is esterified with fatty acids, while a very small part is free. 3-MCPDE and GE have been reported in biscuits, infant formulas, and various types of vegetable oils, especially refined palm oil. The content range of 3-MCPDE was from ND to $10 \mathrm{mg} / \mathrm{kg}$ and that of GE was from ND to $9.1 \mathrm{mg} / \mathrm{kg}$ [3-7].

During the last decade, researchers have investigated the content of 3-MCPDE and GE in oils during the refining process and during food processing. 3-MCPDE and GE were significantly increased in deodorization, one of the refining steps [8]. In addition to being generated in refined oil, 3-MCPDE and GE in oil could migrate into foods during food processing. Owing to its rapid speed and simplicity, deep-frying has been widely used in food processing. Recent studies have found that fried foods contain higher concentrations 
of 3-MCPDE and GE than other types of foods. These contaminants migrate to fried foods from frying oil rather than being formed in the foods themselves during frying [9]. Therefore, it is worthwhile to study the changes in the content of 3-MCPDE and GE in oil during frying.

Many factors, such as heating temperature, heating time, and $\mathrm{NaCl}$ amount, play an important role in the formation of 3-MCPDE and GE during the deodorization stage of oil refining. 3-MCPDE and GE form easily under high temperature and low moisture conditions because the frying oil is decomposed into diacylglycerols (DAGs) and monoacylglycerols (MAGs) by hydrolysis, polymerization, or oxidation. DAGs and MAGs are the most important precursors of 3-MCPDE and GE. Chlorides are also precursors of $3-\mathrm{MCPDE}$ and can promote the formation of GE $[10,11]$. Researchers have found that total polar components (TPC) and color value are highly correlated with 3-MCPDE content [12] There are also some relationships between the degree of oxidation of the frying oil and the amount of 3-MCPDE and GE [13].

Apart from the above influencing factors, many other components present in food may contribute to the formation of 3-MCPDE and GE during heat treatment. For example, researchers found that food type has an important effect on the formation of 3-MCPDE and GE during the frying process. After frying chicken breasts for $100 \mathrm{~min}$ per day for five consecutive days, Wong et al. found that the content of 3-MCPDE in the frying oil was significantly increased while that of GE was decreased [13]. However, an opposite trend for the content of 3-MCPDE and GE occurred in fried potato chips [14]. When different raw materials (meat, cereals, fruit, bulbs, and tubers) were fried in palm oil containing $1.6 \mathrm{mg} / \mathrm{kg}$ of 3-MCPDE, the amount of 3-MCPDE in all of the fried products varied between 0.12 to $0.25 \mathrm{mg} / \mathrm{kg}$ [9]. In addition, different fatty acid compositions may influence the amount of 3-MCPDE or GE. Most of the unrefined oils contained undetectable concentrations of 3-MCPDE and GE, but the refined palm oil and palm olein samples had higher concentrations of both 3-MCPDE and GE than other types of oils. The average content of GE ranged from below the limit of quantification (LOQ) to $4.09 \mathrm{mg} / \mathrm{L}$ for glycidyl palmitate (Pa-GE) and below LOQ to $8.42 \mathrm{mg} / \mathrm{L}$ for glycidyl linoleate (Ol-GE). The average content of 3-MCPDE ranged from below LOQ to $1.92 \mathrm{mg} / \mathrm{L}$ for 1,2-bis-palmitoyl-3-chloropropanediol (Pa-Pa), $0.023 \mathrm{mg} / \mathrm{L}$ to $5.05 \mathrm{mg} / \mathrm{L}$ for palmitoyloleoyl-3-chloropropanediol (Pa-Ol), and $0.028 \mathrm{mg} / \mathrm{L}$ to $2.11 \mathrm{mg} / \mathrm{L}$ for 1,2-bis-oleoyl-3chloropropanediol (Ol-Ol) in refined palm oil [15].

Although previous studies have evaluated the content changes of 3-MCPDE and GE in the frying process, the influences of various foods and frying frequency on 3MCPDE and GE are not clear. Moreover, researchers have not fully studied the effects of different glycerin esters on the changes in 3-MCPDE and GE. Therefore, the present study investigated the effects of food type, frying frequency, and frying temperature on the formation or degradation of 3-MCPDE and GE during the frying process. The color and TPC were measured to establish their relationship with 3-MCPDE or GE. Kinetic models of 3-MCPDE and GE were also established to further understand their formation and degradation rules. Reaction kinetics are a powerful tool for expounding chemical mechanisms that have been applied to 5 -hydroxymethylfurfural, acrylamide, $\beta$-carboline heterocyclic amines, and advanced glycation end products in food research [16-18]. The results of this study would help to control the levels of 3-MCPDE and GE during the frying process.

\section{Materials and Methods}

\subsection{Chemicals}

Isopropanol (IPA) and methanol (HPLC grade) were acquired from Merck KGaA (Darmstadt, Germany). Formic acid (HPLC grade) was purchased from Mreda Technology Inc. (Beijing, China). Ammonium formate (LC/MS grade) was obtained from Fisher Scientific (Waltham, MA, USA). 
Deuterated internal standards, including glycidyl oleate- $d_{5}\left(\mathrm{Ol}-\mathrm{GE}-d_{5}\right)$, glycidyl stearate$d_{5}$ (St-GE- $\left.d_{5}\right), 1,2-$ bis-palmitoyl-3-chloropropanediol- $d_{5}\left(\mathrm{~Pa}-\mathrm{Pa}-d_{5}\right)$, and 1,2-bis-oleoyl-3chloropropanediol- $d_{5}\left(\mathrm{Ol}-\mathrm{Ol}-d_{5}\right)$; 3-MCPDE standards, including 1,2-bis-palmitoyl-3chloropropanediol (Pa-Pa), oleoyl-palmitoyl-3-chloropropanediol (Ol-Pa), 1,2-bis-oleoyl-3chloropropanediol (Ol-Ol), and oleoyl-stearoyl-3-chloropropanediol (Ol-St); glycidyl esters standards, including glycidyl palmitate (Pa-GE), glycidyl linoleate (Li-GE), glycidyl oleate (Ol-GE), and glycidyl stearate (St-GE), were purchased from Toronto Research Chemicals (Toronto, Ontario, Canada). The purity of all the above standards was no less than $98.0 \%$.

Stock solutions of 3-MCPDE (1000 mg/L) and internal standards (250 mg/L) were prepared using ethyl acetate and stored at $-20{ }^{\circ} \mathrm{C}$. The mixed stock solutions ( $\mathrm{Pa}-\mathrm{Pa}, \mathrm{Ol}-\mathrm{Pa}$, Ol-Ol, Ol-St, Pa-GE, Ol-GE, St-GE, and Li-GE at $10 \mathrm{mg} / \mathrm{L}$ ) were prepared by appropriate dilution of the corresponding stock solutions with IPA. The mixed internal standard solutions (St-GE- $d_{5}, \mathrm{~Pa}-\mathrm{Pa}-d_{5}, \mathrm{Ol}-\mathrm{Ol}-d_{5}$, and Ol-GE- $d_{5}$ at $5 \mathrm{mg} / \mathrm{L}$ ) were prepared by diluting the internal stock solutions with IPA. All solutions were stored at $-20{ }^{\circ} \mathrm{C}$.

\subsection{Samples and Pre-Treatment}

Palm oil, fresh chicken breast and potato were acquired from a local market. Potatoes were washed with water and cut into sticks of approximately $1 \times 1 \mathrm{~cm}$ cross-section and $5-10 \mathrm{~cm}$ in length. The sticks were submerged in either 0 or $2 \% \mathrm{NaCl}$ solution for $1 \mathrm{~h}$. The sticks were then blanched in $\mathrm{NaCl}$ solutions with concentrations corresponding to the previous step for $90 \mathrm{~s}$. The two samples were recorded as PS- $0 \% \mathrm{NaCl}$ and PS- $\% \mathrm{NaCl}$. The fresh chicken breast was cut into $3 \times 3 \mathrm{~cm}$ pieces and submerged in 0 or $2 \% \mathrm{NaCl}$ solutions for $1 \mathrm{~h}$. The two samples were recorded as $\mathrm{CB}-0 \% \mathrm{NaCl}$ and $\mathrm{CB}-2 \% \mathrm{NaCl}$.

\subsection{Deep-Fat Frying}

Palm oil $(3.5 \mathrm{~L})$ was poured into a fryer. The temperature was raised to the corresponding temperatures in $10 \mathrm{~min}$ and maintained for $1.0 \mathrm{~h}$ before frying. The pre-treated samples (100 g) were fried for 2.0,1.5, 1.0, and $1.0 \mathrm{~min}$ at the corresponding temperatures of $160,180,200$, and $220^{\circ} \mathrm{C}$. Each hour was a cycle. Potato chips or chicken breasts were fried once in every cycle. In frying frequency parts, chicken breasts were fried once, three times, and five times, respectively. Eight cycles were performed per day. The oil was used continuously for 3 days without any replenishment. At the end of each $4 \mathrm{~h}$ period, $20 \mathrm{~mL}$ of oil was collected and stored in a freezer at $-20{ }^{\circ} \mathrm{C}$ before analysis.

\subsection{Fatty Acid Analysis}

Free fatty acids were methylated and analyzed by gas chromatography based on the Chinese National Standard GB5009.168-2016 [19]. The frying oil samples were saponified and methylated in alkaline condition to form fatty acid methyl ester, which was analyzed by gas chromatographic-mass spectrometry (GC-MS) and quantitatively determined by external standard method.

\subsection{Quantitation of TPC}

TPC were determined using the Chinese National Standard GB5009.202-2016 [20]. The oil sample was separated into two parts: the non-polar and polar fractions after column chromatography (packed with Silica gel 60). The non-polar components were eluted with a mixture of petroleum and diethyl ether $(87: 13, v: v)$, evaporated to nearly dry, and finally vacuum dried to a constant weight; this weight indicated the content of non-polar components. The polar fraction was the remainder of the oil sample: the weight of the original sample minus the content of the non-polar fraction.

\subsection{Color Analysis}

The colors of the fresh oils and the oils after frying were determined using an UltraScan PRO system (Hunter Associates Laboratory, Inc., Reston, VA, USA). The differences in the colors of the samples were determined based on the different $L$, $a$, and $b$ configurations in 
the color system. The color values were expressed as L (whiteness or brightness/darkness), $\mathrm{a}$ (redness/greenness), and $\mathrm{b}$ (yellowness/blueness).

The total color difference $(\Delta E)$ was used to evaluate the changes at different frying times. The values of $\Delta E$ were calculated using the following equation

$$
\Delta E=\sqrt{\left(L_{0}-L_{f}\right)^{2}+\left(a_{0}-a_{f}\right)^{2}+\left(b_{0}-b_{f}\right)^{2}}
$$

where $L_{f}, a_{f}, b_{f}$, represents the color values of thermally treated oil, and $L_{0}, a_{0}, b_{0}$, represents the color values of initial oil.

\subsection{Determination of 3-MCPDE and GE}

A portion of the oil sample $(0.1000 \mathrm{~g})$ was accurately weighed into a sample bottle, and then $20 \mu \mathrm{L}$ of internal standard and $980 \mu \mathrm{L}$ of isopropanol were added. After the sample bottle was vortexed thoroughly, the sample was analyzed using HPLC-MS/MS.

Separation analysis was performed on a 1260 HPLC system (Agilent Technologies, Santa Clara, CA, USA) with an Eclipse Plus C18 $(2.1 \mathrm{~mm} \times 150 \mathrm{~mm}, 5 \mu \mathrm{m}$; Agilent Technologies). The column temperature was maintained at $40^{\circ} \mathrm{C}$. Mobile phase A consisted of methanol/water $(92: 8, v: v)$ with $0.05 \%$ formic acid and $1.0 \mathrm{mmol} / \mathrm{L}$ ammonium formate; the mobile phase B was composed of isopropanol/water $(98: 2, v: v)$ with $0.05 \%$ formic acid and $1.0 \mathrm{mmol} / \mathrm{L}$ ammonium formate. The gradient started at $100 \% \mathrm{~A}$ for the first $2 \mathrm{~min}$, a linear ramp to $75 \%$ A at $8 \mathrm{~min}$, followed by $30 \%$ at $15 \mathrm{~min}$, and then $17 \% \mathrm{~A}$ for $20 \mathrm{~min}$, followed by a linear decrease to $0 \% \mathrm{~A}$ at $25 \mathrm{~min}$, and, finally, re-equilibration for $2 \mathrm{~min}$ before the next injection. The flow rate was $0.30 \mathrm{~mL} / \mathrm{min}$, and the injection volume was $5.0 \mu \mathrm{L}$.

A 6470 Triple Quadrupole Mass Spectrometer (Agilent Technologies) equipped with an electrospray ionization source (ESI) was used in positive mode. Analyst Lab Solutions LC/MS version B.09.00 software was used for the master control of LC and MS. The atomizing gas was nitrogen $\left(\mathrm{N}_{2}>99.999 \%\right)$ at $300{ }^{\circ} \mathrm{C}$. The ion source parameters were as follows: capillary voltage, $3.5 \mathrm{kV}$; gas temperature, $350^{\circ} \mathrm{C}$; drying gas flow, $5.0 \mathrm{~L} / \mathrm{min}$; nebulizer pressure, $0.31 \mathrm{MPa}$; sheath gas temperature, $350{ }^{\circ} \mathrm{C}$; sheath gas flow $\left(\mathrm{N}_{2}>99.999 \%\right)$, $11.0 \mathrm{~L} / \mathrm{min}$.

The retention times of the target compounds were determined by analyzing a mixed standard under the same conditions described above using the dynamic multiple reaction monitoring (dMRM) mode. The precursor-product ion transitions and optimized mass spectrometric parameters, such as the collision energy (CE), are listed in Table 1.

Table 1. MS parameters for GE and 3-MCPDE.

\begin{tabular}{|c|c|c|c|c|c|c|}
\hline Compounds & Abbreviation & RT (min) & $\begin{array}{c}\text { Precursor Ion } \\
{\left[\mathrm{M}+\mathrm{NH}_{4}\right](\mathrm{m} / \mathrm{z})}\end{array}$ & $\begin{array}{l}\text { Production } \\
\qquad(m / z)\end{array}$ & $\begin{array}{c}\text { Collision } \\
\text { Energy (eV) }\end{array}$ & $\begin{array}{l}\text { Internal } \\
\text { Standard }\end{array}$ \\
\hline $\begin{array}{c}\text { GE } \\
\text { Glycidyl linoleate }\end{array}$ & Li-GE & 3.88 & 354.3 & $\begin{array}{l}81.1 * \\
95.1\end{array}$ & $\begin{array}{l}32 \\
28\end{array}$ & Ol-GE- $d_{5}$ \\
\hline Glycidyl palmitate & Pa-GE & 4.77 & 330.3 & $\begin{array}{l}57.2 * \\
71.1\end{array}$ & $\begin{array}{l}32 \\
24\end{array}$ & Ol-GE- $d_{5}$ \\
\hline Glycidyl oleate & Ol-GE & 5.31 & 356.3 & $\begin{array}{c}57.1 * \\
69.1\end{array}$ & $\begin{array}{l}32 \\
36\end{array}$ & Ol-GE- $d_{5}$ \\
\hline Glycidyl stearate & St-GE & 7.65 & 358.3 & $\begin{array}{c}57.2 * \\
71.1\end{array}$ & $\begin{array}{l}36 \\
32\end{array}$ & St-GE- $d_{5}$ \\
\hline 3-MCPDE & & & & & & \\
\hline 1,2-Bis-palmitoyl-3-chloropropanediol & $\mathrm{Pa}-\mathrm{Pa}$ & 18.87 & 604.5 & $\begin{array}{l}331.1 * \\
239.2\end{array}$ & $\begin{array}{l}14 \\
20\end{array}$ & $\mathrm{~Pa}-\mathrm{Pa}-d_{5}$ \\
\hline Oleoyl-palmitoyl-3-chloropropanediol & $\mathrm{Ol}-\mathrm{Pa}$ & 19.05 & 630.5 & $\begin{array}{l}331.3 * \\
357.3\end{array}$ & $\begin{array}{l}20 \\
20\end{array}$ & $\mathrm{~Pa}-\mathrm{Pa}-d_{5}$ \\
\hline 1,2-Bis-oleoyl-3-chloropropanediol & Ol-Ol & 19.21 & 656.5 & $\begin{array}{l}357.3 * \\
265.2\end{array}$ & $\begin{array}{l}22 \\
22\end{array}$ & $\mathrm{Ol}-\mathrm{Ol}-d_{5}$ \\
\hline Oleoyl-stearoyl-3-chloropropanediol & Ol-St & 19.23 & 658.5 & $\begin{array}{c}359.3 * \\
357.3\end{array}$ & $\begin{array}{l}20 \\
24\end{array}$ & $\mathrm{Ol}-\mathrm{Ol}-d_{5}$ \\
\hline
\end{tabular}


Table 1. Cont.

\begin{tabular}{|c|c|c|c|c|c|c|}
\hline Compounds & Abbreviation & RT (min) & $\begin{array}{c}\text { Precursor Ion } \\
{\left[\mathbf{M}+\mathrm{NH}_{4}\right](\mathrm{m} / \mathrm{z})}\end{array}$ & $\begin{array}{l}\text { Production } \\
\qquad(\mathrm{m} / \mathrm{z})\end{array}$ & $\begin{array}{l}\text { Collision } \\
\text { Energy (eV) }\end{array}$ & $\begin{array}{c}\text { Internal } \\
\text { Standard }\end{array}$ \\
\hline \multicolumn{7}{|l|}{ Internal standard } \\
\hline \multirow[t]{2}{*}{ Glycidyl oleate- $d_{5}$} & Ol-GE- $d_{5}$ & 5.23 & 361.0 & $69.3 *$ & 40 & \\
\hline & & & & 83.2 & 28 & \\
\hline \multirow[t]{2}{*}{ Glycidyl stearate- $d_{5}$} & St-GE- $d_{5}$ & 7.56 & 363 & $57.2 *$ & 36 & \\
\hline & & & & 85.1 & 28 & \\
\hline \multirow{2}{*}{ 1,2-Bis-palmitoyl-3-chloropropanediol- $d_{5}$} & $\mathrm{~Pa}-\mathrm{Pa}-d_{5}$ & 18.82 & 609.3 & 239.2 & 24 & \\
\hline & & & & $336.3 *$ & 12 & \\
\hline \multirow{2}{*}{ 1,2-Bis-oleoyl-3-chloropropanediol- $d_{5}$} & $\mathrm{Ol}-\mathrm{Ol}-d_{5}$ & 19.18 & 661.53 & $362.3 *$ & 28 & \\
\hline & & & & 265.1 & 20 & \\
\hline
\end{tabular}

* quantitative ion.

\subsection{Kinetics and Statistical Analysis}

In previous studies, the MCPDE or GE increased linearly with time (zero-order kinetics) according to the following equation [21].

$$
C_{t}=C_{0}+k t
$$

where $C_{0}$ is the initial content of GE or MCPDE (mg/kg), $t$ is the heat treatment time (h), $C_{t}$ is the content at time $t(\mathrm{mg} / \mathrm{kg})$, and $k$ is the rate constant $\left(\mathrm{h}^{-1}\right)$.

The relative root mean square error (RRMSE) represented the sample standard deviation of the differences between the predicted and observed values [22]. The smaller the RRMSE value in comparison to the actual value, the better the goodness of fit. The RRMSE was calculated using the following equation

$$
\operatorname{RRMSE}(\%)=\frac{1}{\bar{y}_{A}} \sqrt{\frac{\sum_{i=1}^{n}\left(y_{A}-y_{M}\right)^{2}}{n}} \times 100
$$

The temperature dependence of simple chemical reactions is empirically described by Arrhenius' law, which is expressed as Equation (4)

$$
k=A e^{-\frac{E_{a}}{R T}}
$$

where $k$ is the reaction rate constant, $A$ is a pre-exponential factor, $E a$ is the activation energy, $T$ is the absolute temperature, and $R$ is the molar gas constant $(8.314 \mathrm{~kJ} / \mathrm{mol} \cdot \mathrm{K})$.

According to Arrhenius' equation (Equation (4)), the activation energy $(E a)$ and Arrhenius prefactor $(A)$ are expressed as a linear equation, and, thus, the logarithm of the rate constant $(\ln k)$ against the reciprocal of the absolute temperature $(1 / \mathrm{T})$ is shown in Equation (5).

$$
\ln k=\ln A-\frac{E_{a}}{R T}
$$

Data are presented as mean \pm standard deviation (SD) from duplicate experiments using Excel 2007 (Microsoft Corp, Seattle, WA, USA). The Pearson range tests were used to determine the significant correlation coefficients $(p \leq 0.05)$ between 3-MCPDE, GE, and some of the examined parameters (TPC and color analysis). The 3-MCPDE and GE content in all figures were analyzed by one-way analysis of variance and Duncan's multiple tests to identify significant differences $(p \leq 0.05)$ in the comparison of means. All analyses were performed using SPSS 20.0 (SPSS Inc., Chicago, IL, USA). All plots were determined using Origin 9.0.0 (Northampton, MA, USA). 


\section{Results}

\subsection{HPLC-MS/MS Analysis}

The advantage of the direct analysis method is simplicity, and provides information about the fatty acid composition of 3-MCPDE and GE; however, a large number of standards are used during the analysis [23]. To achieve a balance between cost minimization and accurate quantitation, the fatty acid profiles of the palm oil were analyzed and are shown in Table S1. The predominant fatty acids were palmitic and oleic acids, which accounted for more than $80 \%$ of the fatty acids, followed by linoleic and stearic acids. Other fatty acids occurred to a lesser extent. Palmitic acid was the primary fatty acid in palm oil, whereas it was less abundant in other oils. The fatty acid composition of palm oil was similar to that of crude palm oil and preneuralized crude palm oil analyzed by Chaijan [24]. Therefore, the content of 3-MCPDE, consisting of palmitic and oleic acids, was analyzed in the oil samples.

For HPLC-MS/MS analysis, the dMRM model was used for scanning with one quantitation and two identification ions to avoid false-positive responses. The 3-MCPDE and GE were identified by their retention times and monitored characteristic ions (Table 1).

Standard solutions with different concentrations $(0.05,0.10,0.20,0.50$, and $1.00 \mathrm{mg} / \mathrm{L}$ for each GE; 0.010, 0.020, 0.050, 0.10, 0.20, 0.50, and $1.00 \mathrm{mg} / \mathrm{L}$ for every 3-MCPDE) and internal solution with $0.100 \mathrm{mg} / \mathrm{L}$ for both deuteration GE and 3-MCPDE were analyzed as the samples. Thereafter, the calibration curves were obtained using a least-squares linear regression analysis of the ratio of target standards to internal peak area versus the ratio of the corresponding concentrations. The calibration curves of the four target 3-MCPDE were linear in the range of $0.010-1.00 \mathrm{mg} / \mathrm{L}$, and those of the four target GEs were linear in the range of $0.050-1.00 \mathrm{mg} / \mathrm{L}$, with a correlation coefficient no less than 0.99 , as shown in Table S2. The limits of detections (LODs) and limits of quantifications (LOQs) of the method were calculated as the analyte concentrations with signal-to-noise $(\mathrm{S} / \mathrm{N})$ ratios of 3 and 10 , respectively. The $\mathrm{S} / \mathrm{N}$ ratios were estimated based on the peak heights of the identified ions. The LODs for 3-MCPDE and GE were in the ranges of $0.0002-0.0003 \mathrm{mg} / \mathrm{kg}$ and $0.0004-$ $0.0100 \mathrm{mg} / \mathrm{kg}$, respectively. The LOQs for 3-MCPDE and GE were $0.0004-0.010 \mathrm{mg} / \mathrm{kg}$ and $0.0050-0.0500 \mathrm{mg} / \mathrm{kg}$, respectively.

To establish the suitability of the above method for the determination of 3-MCPDE and GE in edible oils, the accuracy and repeatability of the analysis method were determined. The chicken breast fried for $12 \mathrm{~h}$ in oil was chosen as the spiked sample, to which 1.00 to $3.00 \mathrm{mg} / \mathrm{kg}$ standard solutions were added. The extracted ion chromatogram was shown in Figure S1. Each spiked sample was subjected to six trials. The average recoveries of 3-MCPDE and GE ranged from 81.3 to $106.4 \%(0.90-8.1 \%$ RSD). The results of the recovery experiments (Table S3) showed that the overall average recoveries and repeatabilities (RSD) were 84.9 to $103 \%$ and 0.90 to $7.3 \%$ for $3-\mathrm{MCPDE}$, and 81.3 to $106.4 \%$ and 3.2 to $8.1 \%$ for GE, respectively.

\subsection{Influence of Foods Types}

Previous studies have indicated that the concentrations of 3-MCPDE and GE vary in different frying foods [25]. In the present study, potatoes and chicken breasts were used as representatives of high-carbohydrate and high-protein foods, respectively. As shown in Figure 1, the effect of food type on the changes of 3-MCPDE and GE content were significant. The GE content in the oil after frying chicken breasts decreased more than that after frying potato chips. The decline rate of $\mathrm{GE}$ was lower in the presence of $\mathrm{NaCl}$, and the GE content in the frying oil decreased faster after frying CB-2\% $\mathrm{NaCl}$ than that after frying $\mathrm{PS}-2 \% \mathrm{NaCl}$. The content of 3-MCPDE in the oil decreased the least after frying PS-2\% $\mathrm{NaCl}$, followed by that after frying $\mathrm{CB}-0 \% \mathrm{NaCl}$ and $\mathrm{PS}-0 \% \mathrm{NaCl}$, which decreased the most. Interestingly, the 3-MCPDE content increased in the frying oil used for CB- $\% \mathrm{NaCl}$. In general, MCPDE formed more easily in the oil used for frying chicken than that used for frying potatoes, while GE did the opposite. However, this might be because the chicken has more 3-MCPDE precursors. For example, chickens contain more lipids, but potatoes 
have almost no lipids. Furthermore, researchers have found that the total fatty acids are approximately $2.5 \mathrm{~g} / 100 \mathrm{~g}$ in skinless chicken breast [26]. Fatty acids can form DAG, which has been identified as a precursor of MCPDE [27]. In contrast, potatoes contain several antioxidants, such as vitamins (B1, B6, B9, and C), carotenoids, and phenylpropanoids [28], which may inhibit the formation of MCPDE and GE. Although these compounds have not been confirmed to inhibit MCPDE and GE formation, other antioxidants have proven their inhibiting capacity, including butylated hydroxytoluene (BHT), butylated hydroxyanisole (BHA), tert-butyl hydroquinone (TBHQ), propyl gallate (PG), L-ascorbyl palmitate (AP), and $\alpha$-tocopherol (VE) [29].

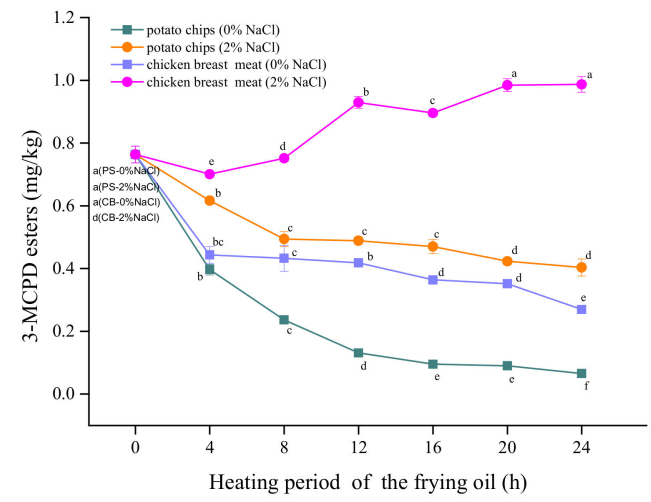

(A)

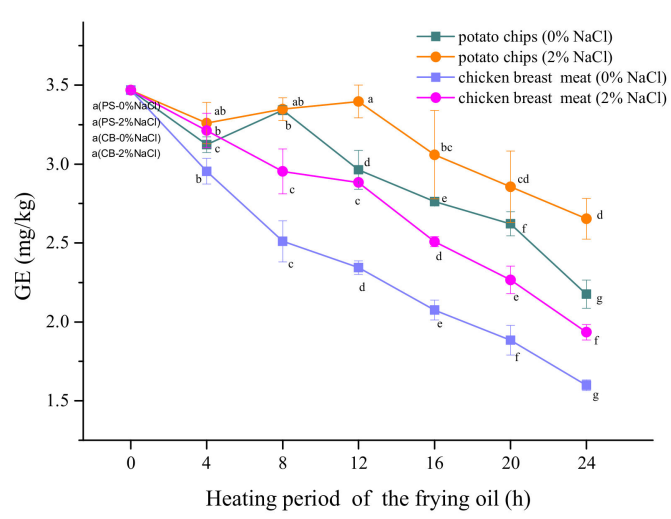

(B)

Figure 1. The content of (A) MCPDE and (B) GE fried oils of different heating periods after frying potato chips or chicken breast. Within each line, points with different letters are significantly $(p<0.05)$ different from each other.

The content of 3-MCPDE was significantly higher in the $\mathrm{CB}-2 \% \mathrm{NaCl}$ frying oil than that of $\mathrm{CB}-0 \% \mathrm{NaCl}$. This may be because the chloride anion can react with acylglycerol to form 3-MCPDE. This phenomenon has also been observed in other studies. For example, when the proportion of $\mathrm{NaCl}$ solution was increased from 0 to $60 \mathrm{~g} / 100 \mathrm{~g}$, the amount of 3-MCPDE sharply increased [7]. However, the formation rate of 3-MCPDE was lower than that of frying potatoes, as shown in Figure 1. Therefore, there was an overall decreasing trend for 3-MCPDE in the potato frying model.

Although the contents of GE were decreased both in the oils of frying potato chips and chicken breasts, the content of GE during frying of the samples with $2 \% \mathrm{NaCl}$ was lower than that of the samples without $\mathrm{NaCl}$, despite the formation of $\mathrm{GE}$ without chloride, unlike $\mathrm{NaCl}$ in 3-MCPDE. This phenomenon may be caused by chlorine-containing compounds, which promote the formation of GE. Although 3-MCPDE and GE can be transformed to each other, the transformation rate from MCPDE to GE is much higher [10].

\subsection{Relationships between the Contents of 3-MCPDE/GE and TPC/Color}

The analysis of 3-MCPDE and GE was complicated and time-consuming, and the assessment of TPC or the total color difference $(\Delta E)$ was relatively easy. TPC and color can be used as standards to evaluate oil quality [30,31]. In China, GB 7102.2-2003 stipulates that the TPC level in frying oil must be below $27 \%$. The color of the frying oil darkens with increasing frying time [31]. Previous studies have used Pearson correlation analysis to assess the relationship between TPC levels and 3-MCPDE concentrations in fish processing [12]. However, the research was not comprehensive regarding the relationships between 3-MCPDE or GE and TPC or color values with different types of food and concentrations of $\mathrm{NaCl}$ during frying. In this case, the TPC content and the total color difference $(\triangle E)$ were analyzed, and the relationships between TPC or $\triangle \mathrm{E}$ and 3-MCPDE or GE were determined by Pearson correlation analysis. 
The graph (Figure S2) shows that $\Delta E$ increases as the frying time increases. There was a significant correlation $(p<0.05)$ between $\Delta E$ and frying time with the oil becoming darker as frying time increased. Other researchers have also noted the changes in the color of the oil during frying. For instance, Abdulkarim considered that the color value of red and yellow in edible oil increased after 5 days of frying [32]. As shown in Table 2, high correlation coefficients $(r=0.866-0.941)$ were observed during the frying process between the 3-MCPDE content and color value. The GE content in the oil used for frying chicken breast also correlated well with the color value $(r=-0.895$ to -0.943$)$ of the frying oil. However, low correlation coefficients $(r=-0.542$ to -0.765$)$ were observed between the GE content in the oil used for frying potato chips and the color value of the frying oil.

Table 2. Correlation analysis between 3-MCPDE or GE and TPC or $\triangle E$ value.

\begin{tabular}{|c|c|c|c|c|c|c|}
\hline & \multicolumn{2}{|c|}{$\begin{array}{c}\text { Correlation }(r) \text { of } \\
\text { MCPD Esters and GE } \\
\text { in the Frying Oil } \\
(\mu \mathrm{g} / \mathrm{kg}) \text { with } \Delta E \text { Value }\end{array}$} & \multicolumn{2}{|c|}{$\begin{array}{c}\text { Correlation }(r) \text { of } \\
\text { MCPD Esters and GE in } \\
\text { the Frying Oil }(\mu \mathrm{g} / \mathrm{kg}) \\
\text { with the TPC Value [\%] }\end{array}$} & \multirow{2}{*}{$\begin{array}{c}\text { Correlation of } \Delta E \text { in } \\
\text { the Frying Oil with the } \\
\text { Different Heating } \\
\text { Hour }\end{array}$} & \multirow{2}{*}{$\begin{array}{l}\text { Correlation of TPC in } \\
\text { the Frying Oil with the } \\
\text { Different Heating } \\
\text { Hour }\end{array}$} \\
\hline & 3-MCPDE & GE & 3-MCPDE & GE & & \\
\hline Potato chips $(0 \% \mathrm{NaCl})$ & $-0.992 * *$ & -0.765 & $-0.892 *$ & $-0.916^{*}$ & $0.937 * *$ & $0.973 * *$ \\
\hline Potato chips $(2 \% \mathrm{NaCl})$ & $-0.954^{* *}$ & -0.542 & $-0.935 *$ & -0.811 & $0.866^{*}$ & $0.991 *$ \\
\hline Chicken breast meat $(0 \% \mathrm{NaCl})$ & -0.781 & $-0.943^{* *}$ & $-0.961 *$ & $-0.912 *$ & $0.909 *$ & $0.956 *$ \\
\hline Chicken breast meat $(2 \% \mathrm{NaCl})$ & $0.949 *$ & $-0.895 *$ & 0.857 & $-0.990 * *$ & $0.941 * *$ & $0.979 *$ \\
\hline
\end{tabular}

${ }^{*}$ significant correlation coefficients $(p \leq 0.05) ;{ }^{* *}$ extremely significant coefficients $(p \leq 0.01)$.

The determination of polar compound content in frying oils provides the most reliable index of the extent of oxidative degradation. The TPC content increased almost linearly with frying time (Figure S3). There was a significant correlation $(p<0.05)$ between TPC and frying time. During frying, new polar compounds are formed; thus, the proportions of DAG, MAG, and FFA increased. Significant correlation was also observed between the 3-MCPDE contents and TPC values $(r=-0.892$ to -0.961$)$ and between GE contents and TPC values $(r=-0.912$ to -0.941$)$ in most situations. However, the correlation between the 3-MCPDE content in the frying oil used for CB-2\% NaCl and the TPC values was not statistically significant. Similarly, there was a non-significant correlation between the GE content in the frying oil of PC- $2 \% \mathrm{NaCl}$ and the TPC values.

Based on these results, it is suggested that both the TPC and the color values of the frying oils could be regarded as concentration prediction tools for 3-MCPDE and GE to a large extent, although not all of them were significantly correlated statistically. Furthermore, Merkle proposed that TPC and color values could be used as screening methods for estimating the amount of 3-MCPDE and GE in fish products [12]. Thus, color and TPC values could be used to estimate the contents of 3-MCPDE and GE, especially 3-MCPDE.

\subsection{Influence of the Frying Frequency}

According to the above experimental results, the GE content of palm oil declined during the frying process, while that of 3-MCPDE was only increased in the frying oil of $\mathrm{CB}-2 \% \mathrm{NaCl}$. Therefore, to study the formation rules of 3-MCPDE, $\mathrm{CB}-2 \% \mathrm{NaCl}$ fried in palm oil was used as the target sample. Differences in frying frequency may be related to the degree of TAG hydrolysis during frying. However, no studies have discussed the relationships between frying frequency and the content of 3-MCPDE and GE. Therefore, the relationship between the frying frequency and the contents of 3-MCPDE and GE is further discussed. 
In the present study, three frying frequencies, one, three, and five times per hour, were considered in the experiment. The results are shown in Figure 2; the concentrations of 3-MCPDE in the three frying systems increased from 29.2 to $55.0 \%$ over the entire frying duration, although its content decreased for $0-4 \mathrm{~h}$, regardless of frying frequency per hour. Unlike the linear increase in 3-MCPDE content with frying frequencies of one and five after $4 \mathrm{~h}$, the content increase in 3-MCPDE after frying three times increased sharply from 4 to $12 \mathrm{~h}$, then declined slightly after $12 \mathrm{~h}$, and finally increased sharply at 20-24 h. It is worth noting that the percentage increased the highest (55.0\%) when frying three times per hour. When the frying frequency increased from once to three times, more water molecules in the chicken breast may have reacted with TAG, causing an increase in TAG hydrolyzation. As mentioned above, TAG can be hydrolyzed to DAG and MAG, which are precursor substances of 3-MCPDE during frying. When the frying frequency was increased to five times, the water accelerated the degradation of 3-MCPDE. This phenomenon was also demonstrated by Zhou [33]. They found that 3-MCPDE increased significantly (approximately $3000 \mathrm{mg} / \mathrm{kg}$ ) as the water content increased from 1 to $10 \%$ under palm oil frying. However, as the heating time increased, the 3-MCPDE content declined after $2 \mathrm{~h}$.

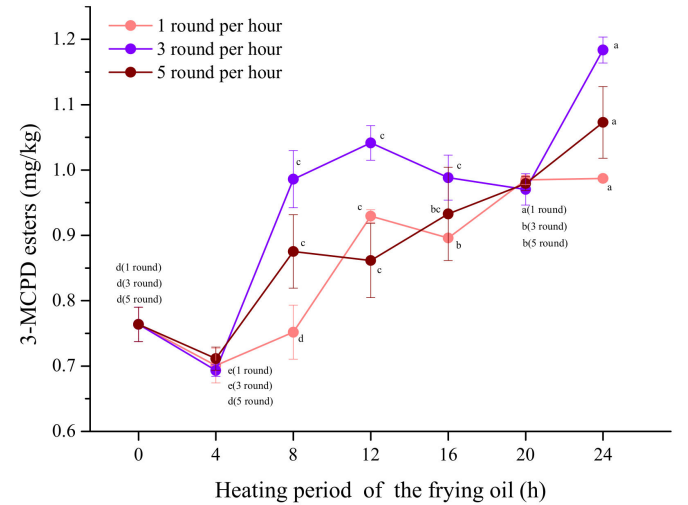

(A)

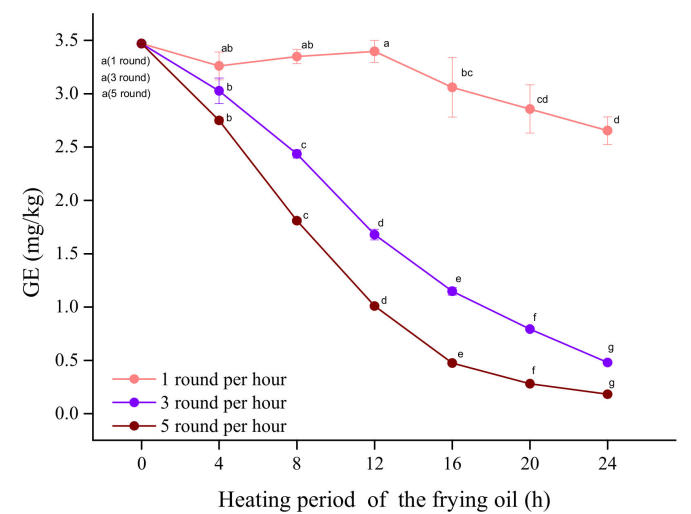

(B)

Figure 2. The content of (A) MCPDE and (B) GE fried oils of different heating periods after frying chicken breast 1,3 , or 5 times per hour. Within each line, points with different letters are significantly $(p<0.05)$ different from each other.

As the frying frequency increased, the GE content declined steeply when frying three and five times (86.2-94.8\%). A similar study found that GE was reduced by more than three quarters and one half in palm oil and rapeseed oil, respectively, during intermittent frying for $40 \mathrm{~h}$ [34]. Researchers have pointed out that GE is unstable and degrades more rapidly during high temperature exposure in $2 \mathrm{~h} \mathrm{[35],} \mathrm{which} \mathrm{explains} \mathrm{the} \mathrm{continuing} \mathrm{decline} \mathrm{of} \mathrm{the}$ GE content during the frying process.

\subsection{Influence of Frying Temperature}

According to the broken line graph shown in Figure 3, as the temperature increased from 140 to $180^{\circ} \mathrm{C}$, the content of 3-MCPDE increased in all frying for $24 \mathrm{~h}$. At 200 and $220^{\circ} \mathrm{C}$, the contents of 3-MCPDE increased and then decreased, and the two maximum concentrations occurred at 4 and $8 \mathrm{~h}$, respectively. Thus, high temperatures promoted 3-MCPDE formation to a certain extent. Similarly, when the temperature increased from 220 to $260^{\circ} \mathrm{C}$, the content of 3-MCPDE increased within $1.5 \mathrm{~h}$ during peanut oil deodorization [27]. During thermal processing, DAG, MAG, and other polar products (e.g., free fatty acids) from the hydrolyzed TAG can form acyloxonium ions, which react with chloride ions to form 3-MCPDE. Thus, higher temperatures could accelerate the hydrolysis of TAG, resulting in a high 3-MCPDE content. However, the high temperature affects not only the formation of 3-MCPDE but also its degradation. For instance, when pure 3-MCPDE was 
heated at temperatures from $180-260{ }^{\circ} \mathrm{C}$, the degradation percentages ranged from 30 to $70 \%$ over $24 \mathrm{~h} \mathrm{[36].}$

The GE content declined at frying temperatures from 140 to $220^{\circ} \mathrm{C}$. The higher GE content was at relatively low frying temperatures $\left(140-180{ }^{\circ} \mathrm{C}\right)$ than at higher frying temperatures $\left(200-220^{\circ} \mathrm{C}\right)$, as shown in Figure 3. This indicates that GE degraded more rapidly at higher frying temperatures. Recently, a similar study reported that GE levels decreased after $2 \mathrm{~h}$ at $200^{\circ} \mathrm{C}$ in a DAG model in an ampoule bottle [35]. A review article [37] also pointed out that the degradation rate of GE was higher than its formation rate at higher temperatures.

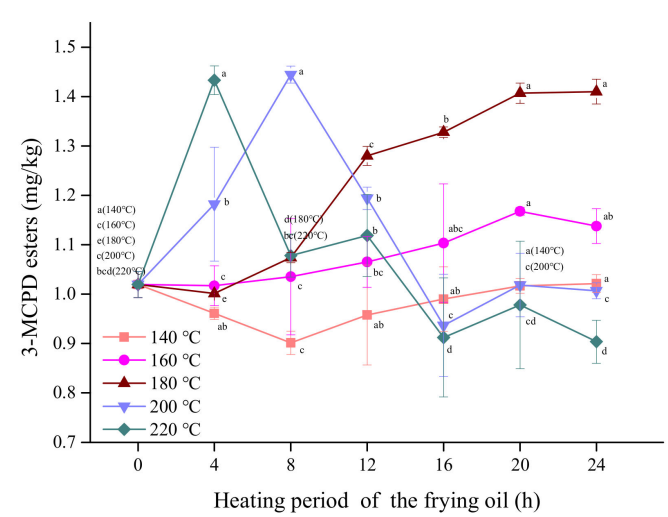

(A)

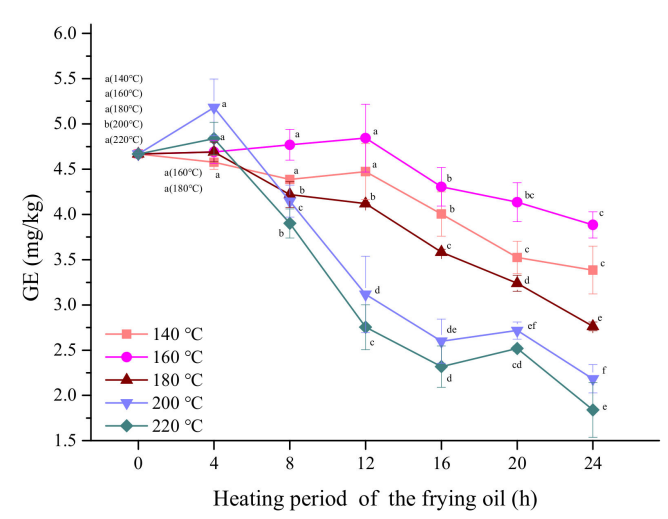

(B)

Figure 3. The content of (A) MCPDE and (B) GE fried oils of different heating periods after frying chicken breast under $140{ }^{\circ} \mathrm{C}, 160{ }^{\circ} \mathrm{C}, 180{ }^{\circ} \mathrm{C}, 200^{\circ} \mathrm{C}$, and $220^{\circ} \mathrm{C}$, respectively. Within each line, points with different letters are significantly $(p<0.05)$ different from each other.

\subsection{Kinetics Analysis}

To further elucidate the formation of MCPDE during frying, a kinetics analysis of 3-MCPDE was performed during heating at 140,160 , and $180^{\circ} \mathrm{C}$ for $24 \mathrm{~h}, 200^{\circ} \mathrm{C}$ for $8 \mathrm{~h}$, and $220^{\circ} \mathrm{C}$ for $4 \mathrm{~h}$, in which 3-MCPDE was increased (Figure S4). Meanwhile, a kinetics analysis of GE was conducted during heating from $140{ }^{\circ} \mathrm{C}$ to $220^{\circ} \mathrm{C}$ for $24 \mathrm{~h}$. GE contents decreased as the frying temperature increased; therefore, the degradation kinetics of GE during frying were further established.

Researchers believe that glycerin ester is a precursor of GE and 3-MCPDE in vegetable oil. Previous studies revealed that the formation rate was affected by various types of oil. However, there are few articles illustrating the kinetics [38]. In the present study, each of the four 3-MCPDE and GE models was established by plotting $\left(C-\mathrm{C}_{0}\right)$ against time. The results are shown in Table 3 where the linear curves fitted the data, indicating zero-order reaction kinetics for 3-MCPDE formation and GE degradation. From Table 3, the formation rate constants (k) of Ol-Pa, Ol-Ol, and Ol-St increased from $4.40 \times 10^{-3}$ to $56.88 \times 10^{-3} / \mathrm{h}$, $1.98 \times 10^{-3}$ to $22.83 \times 10^{-3} / \mathrm{h}$, and $2.03 \times 10^{-3}$ to $23.13 \times 10^{-3} / \mathrm{h}$, respectively, with an increase in temperature $\left(160-220^{\circ} \mathrm{C}\right)$. The formation rate constant of Pa-Pa increased from 160 to $200^{\circ} \mathrm{C}$, except at $220^{\circ} \mathrm{C}$. This is because the formation and degradation of 3-MCPDE occurred simultaneously, and the degradation rate was higher than the formation rate at $220^{\circ} \mathrm{C}$ compared with $200^{\circ} \mathrm{C}$. The degradation rate constant of the four types of GE increased with increasing temperature in the range of $140-220^{\circ} \mathrm{C}$, as shown in Table 3. A similar study also found that the degradation rate constant of GE increased from 1.21 to $2.95 \mathrm{~h}^{-1}$ with an increase in temperature from 120 to $240{ }^{\circ} \mathrm{C}$, which is much higher than the formation rate constant [35]. 
Table 3. Kinetic parameters of 3-MCPDE formation and GE degradation at various temperatures $\left(140-220^{\circ} \mathrm{C}\right)$ in palm oil during frying chicken breast.

\begin{tabular}{|c|c|c|c|c|c|c|c|c|c|}
\hline & & \multicolumn{5}{|c|}{$\mathrm{T}\left({ }^{\circ} \mathrm{C}\right)$} & \multicolumn{3}{|c|}{ Arrhenius Equation } \\
\hline & & 140 & 160 & 180 & 200 & 220 & $A\left(h^{-1}\right)$ & $\mathrm{Ea}(\mathrm{kJ} / \mathrm{mol})$ & $\mathbf{R}^{2}$ \\
\hline \multirow[t]{3}{*}{$\mathrm{Pa}-\mathrm{Pa}$} & $\mathrm{K}\left(\times 10^{-3}, \mathrm{~h}^{-1}\right)$ & - & 2.66 & 4.06 & 14.61 & 10.41 & $6.89 \times 10^{5}$ & 41.05 & 0.81 \\
\hline & $R^{2}$ & - & 0.914 & 0.953 & 0.861 & 0.863 & & & \\
\hline & RRMSE\% & - & 22.82 & 14.57 & 29.84 & 15.42 & & & \\
\hline \multirow[t]{3}{*}{ Ol-Pa } & $\mathrm{K}\left(\times 10^{-3}, \mathrm{~h}^{-1}\right)$ & 4.22 & 4.40 & 9.36 & 46.14 & 56.88 & $7.46 \times 10^{4}$ & 53.58 & 0.89 \\
\hline & $R^{2}$ & 0.937 & 0.85 & 0.958 & 0.794 & 0.863 & & & \\
\hline & RRMSE\% & 17.49 & 20.24 & 7.51 & 12.28 & 23.16 & & & \\
\hline \multirow[t]{3}{*}{$\mathrm{Ol-Ol}$} & $\mathrm{K}\left(\times 10^{-3}, \mathrm{~h}^{-1}\right)$ & - & 1.98 & 2.84 & 10.93 & 22.83 & $5.86 \times 10^{5}$ & 65.09 & 0.95 \\
\hline & $R^{2}$ & - & 0.884 & 0.676 & 0.865 & 0.878 & & & \\
\hline & RRMSE\% & - & 20.40 & 30.14 & 28.83 & 14.10 & & & \\
\hline \multirow[t]{3}{*}{ Ol-St } & $\mathrm{K}\left(\times 10^{-3}, \mathrm{~h}^{-1}\right)$ & - & 2.03 & 3.18 & 14.03 & 23.13 & $8.39 \times 10^{5}$ & 66.00 & 0.93 \\
\hline & $R^{2}$ & - & 0.835 & 0.832 & 0.843 & 0.884 & & & \\
\hline & RRMSE\% & - & 26.83 & 22.27 & 29.66 & 13.23 & & & \\
\hline \multirow[t]{3}{*}{ Li-GE } & $\mathrm{K}\left(\times 10^{-3}, \mathrm{~h}^{-1}\right)$ & 19.11 & 26.76 & 30.92 & 52.38 & 49.29 & 7.06 & 18.49 & 0.93 \\
\hline & $R^{2}$ & 0.99 & 0.966 & 0.988 & 0.823 & 0.947 & & & \\
\hline & RRMSE\% & 6.86 & 25.95 & 4.46 & 27.09 & 12.10 & & & \\
\hline \multirow[t]{3}{*}{ Pa-GE } & $\mathrm{K}\left(\times 10^{-3}, \mathrm{~h}^{-1}\right)$ & 16.85 & 16.48 & 23.86 & 59.04 & 50.57 & 38.91 & 24.88 & 0.81 \\
\hline & $R^{2}$ & 0.925 & 0.893 & 0.828 & 0.951 & 0.962 & & & \\
\hline & RRMSE\% & 5.52 & 22.06 & 16.15 & 26.12 & 16.49 & & & \\
\hline \multirow[t]{3}{*}{ St-GE } & $\mathrm{K}\left(\times 10^{-3}, \mathrm{~h}^{-1}\right)$ & 7.42 & 6.00 & 9.17 & 37.23 & 34.01 & 2.01 & 20.89 & 0.96 \\
\hline & $R^{2}$ & 0.931 & 0.958 & 0.805 & 0.958 & 0.949 & & & \\
\hline & RRMSE\% & 14.53 & 17.41 & 17.97 & 16.29 & 21.04 & & & \\
\hline \multirow[t]{3}{*}{ Ol-GE } & $\mathrm{K}\left(\times 10^{-3}, \mathrm{~h}^{-1}\right)$ & 2.44 & 3.52 & 5.89 & 6.28 & 7.72 & 145.22 & 32.06 & 0.72 \\
\hline & $R^{2}$ & 0.806 & 0.945 & 0.945 & 0.925 & 0.951 & & & \\
\hline & RRMSE\% & 28.58 & 24.28 & 9.06 & 21.06 & 21.80 & & & \\
\hline
\end{tabular}

To illustrate which glycerin esters were dominant, a further study was conducted comparing their corresponding Ea values. The Ea values for the different glycerin esters were calculated according to the Arrhenius equation (Equation (3)). Ea values and corresponding exponential factors of the four 3-MCPDE in order from high to low were $66.00 \mathrm{~kJ} / \mathrm{mol}$ (exponential factor: $8.39 \times 10^{5} \mathrm{~h}^{-1}$, the same as following), $65.09 \mathrm{~kJ} / \mathrm{mol}$ $\left(5.86 \times 10^{5} \mathrm{~h}^{-1}\right), 53.58 \mathrm{~kJ} / \mathrm{mol}\left(7.46 \times 10^{4} \mathrm{~h}^{-1}\right)$, and $41.05 \mathrm{~kJ} / \mathrm{mol}\left(6.89 \times 10^{5} \mathrm{~h}^{-1}\right)$ for Ol-St, $\mathrm{Ol}-\mathrm{Ol}, \mathrm{Ol}-\mathrm{Pa}$, and $\mathrm{Pa}-\mathrm{Pa}$, respectively. This implied that due to the lower Ea, palm glyceride easily formed 3-MCPDE compared with other types of glycerides, such as $\mathrm{Ol}$ and St. This could explain why palm oil was more inclined to form 3-MCPDE than other types of oil because a large proportion of palm glyceride exists in palm oil. Some researchers have also shown that the content of 3-MCPDE is higher in palm oil than in other types of oil during deodorization $[39,40]$. Based on the molecular reaction mechanism, the energy barriers for the formation of $\mathrm{Pa}-\mathrm{Pa}, \mathrm{Ol}-\mathrm{Ol}$, and $\mathrm{Ln}-\mathrm{Ln}$ were $81.012,83.896$, and $79.109 \mathrm{~kJ} / \mathrm{mol}$, respectively, under water conditions. Pa-Pa is formed more easily than Ol-Ol because it crosses the energy barrier more easily at high temperatures [11].

The Ea of Li-GE, Pa-GE, St-GE, and Ol-GE was 18.49, 24.88, 20.89, and $32.06 \mathrm{~kJ} / \mathrm{mol}$, respectively. They are all lower than the formation Ea of $34.58 \mathrm{~kJ} / \mathrm{mol}$ during the formation process [35]. Based on these results, it can be speculated that the degradation of GE is dominant compared with its formation, especially in Li-GE because it has the lowest Ea value. In addition, according to the above Ea values, there are different degradation rates in different types of GE. Unlike the formation of GE, the degradation reaction mechanism is not mediated by free radicals. At high temperatures, GE is degraded into MAG, fatty acid, and glycerol via a ring-opening reaction and continues to be quickly decomposed into hydrocarbons, aldehydes, and $\mathrm{CO}_{2}$ in addition to polar compounds [41].

\section{Conclusions}

The present study established a direct analysis method with good accuracy and precision using HPLC-MS/MS with AMRM for 3-MCPDE and GE. The formation of 3$\mathrm{MCPDE}$ was affected by the $\mathrm{NaCl}$ content, temperature, and time in palm oil during frying. 
3-MCPDE is formed more easily in chicken breasts than in potato chips. The GE content in frying oils decreased with increasing frying time during chicken breast and potato chip frying. The frying frequency had an important effect on the formation of 3-MCPDE and the decrease in GE in frying oils. The formation of 3-MCPDE and degradation of GE followed zero-order reactions. Pa-Pa is more likely to form than the other three 3-MCPDE, and Li-GE is easily degraded because of its low Ea values. The content of 3-MCPDE in palm oil is higher than that in other edible oils because of the high content of palmitic glycerides. This study provides a novel insight into the formation of 3-MCPDE and degradation of GE, which offers a theoretical basis for the efficient inhibition of 3-MCPDE and GE in foods.

Supplementary Materials: The following are available online at https: / / www.mdpi.com/article/10.3 390/foods10102266/s1, Figure S1: Extracted ion chromatogram of: (a) Li-GE, (b) Pa-GE, (c) Ol-GE, (d) St-GE, (e) Pa-Pa, (f) Ol-Pa, (g) Ol-St, (h) Ol-Ol in the fried palm olein sample after frying for $4 \mathrm{~h}$ at $200{ }^{\circ} \mathrm{C}$, Figure S2: $\Delta E$ value in fried oils of different heating period after frying potato chips and chicken breasts, Figure S3: TPC amount in fried oils of different heating period after frying potato chips and chicken breasts, Figure S4: Contents of 3-MCPDE in fried oils after frying chicken breasts at $220^{\circ} \mathrm{C}$ for $0-4 \mathrm{~h}$ and at $200{ }^{\circ} \mathrm{C}$ for $0-8 \mathrm{~h}$, Table S1: Fatty acid profile (g/100 g lipid) of palm oil, Table S2: Calibration curves, correlation coefficients $(r)$, LODs and LOQs for GEs and 3-MCPDE, Table S3: Recovery and repeatability results of GEs and 3-MCPDE analysis.

Author Contributions: Conceptualization, J.Z.; Data curation, W.Z.; Formal analysis, J.Z.; Funding acquisition, M.H. and B.S.; Investigation, J.Z.; Methodology, Y.Z.; Project administration, M.H.; Supervision, M.H.; Validation, W.Z. and M.H.; Visualization, J.Z.; Writing-original draft, J.Z.; Writing-review and editing, M.H. All authors have read and agreed to the published version of the manuscript.

Funding: This research was funded by National Key Research and Development Program of China (2017YFC1600401-3).

Informed Consent Statement: Not applicable.

Data Availability Statement: Not applicable.

Conflicts of Interest: All authors declare no conflict of interest.

\section{References}

1. IARC Working Group on the Evaluation of Carcinogenic Risks to Humans. IARC monographs on the evaluation of carcinogenic risk of chemicals to humans. In IARC Monographs on the Evaluation of Carcinogenic Risk of Chemicals to Humans; IARC: Lyon, France, 2000; pp. 469-486.

2. European Food Safety Authority. Risks for Human Health Related to the Presence of 3- and 2-Monochloropropanediol (MCPD), and Their Fatty Acid Esters, and Glycidyl Fatty Acid Esters in Food. EFSA J. 2016, 4, 4426-4585.

3. Kuhlmann, J. Determination of bound 2,3-epoxy-1-propanol (glycidol) and bound monochloropropanediol (MCPD) in refined oils. Eur. J. Lipid Sci. Technol. 2011, 113, 335-344. [CrossRef]

4. Chung, H.; Chung, S.W.; Chan, B.; Ho, Y.Y.; Xiao, Y. Dietary exposure of Hong Kong adults to fatty acid esters of 3monochloropropane-1,2-diol. Food Addit. Contam. Part A 2013, 30, 1508-1512. [CrossRef]

5. Spungen, J.H.; MacMahon, S.; Leigh, J.; Flannery, B.; Kim, G.; Chirtel, S.; Smegal, D. Estimated US infant exposures to 3-MCPD esters and glycidyl esters from consumption of infant formula. Food Addit. Contam. Part A 2018, 35, 1085-1092. [CrossRef] [PubMed]

6. Haines, T.D.; Adlaf, K.J.; Pierceall, R.M.; Lee, I.; Venkitasubramanian, P.; Collison, M.W. Direct Determination of MCPD Fatty Acid Esters and Glycidyl Fatty Acid Esters in Vegetable Oils by LC-TOFMS. J. Am. Oil Chem. Soc. 2010, 88, 1-14. [CrossRef] [PubMed]

7. Li, C.; Zhou, Y.; Zhu, J.; Wang, S.; Nie, S.; Xie, M. Formation of 3-chloropropane-1,2-diol esters in model systems simulating thermal processing of edible oil. LWT 2016, 69, 586-592. [CrossRef]

8. Franke, K.; Strijowski, U.; Fleck, G.; Pudel, F. Influence of chemical refining process and oil type on bound 3-chloro-1,2-propanediol contents in palm oil and rapeseed oil. LWT 2009, 42, 1751-1754. [CrossRef]

9. Arisseto, A.P.; Marcolino, P.F.C.; Augusti, A.C.; Scaranelo, G.R.; Berbari, S.A.G.; Miguel, A.M.R.O.; Morgano, M.A.; Vicente, E. Contamination of Fried Foods by 3-Monochloropropane-1,2-diol Fatty Acid Esters During Frying. J. Am. Oil Chem. Soc. 2017, 94, 449-455. [CrossRef]

10. Wang, S.; Liu, G.; Cheng, W. Chloride-mediated co-formation of 3-monochloropropanediol esters and glycidyl esters in both model vegetable oils and chemical model systems. Food Res. Int. 2021, 140, 109879. [CrossRef] 
11. Yao, Y.; Cao, R.; Liu, W.; Zhou, H.; Li, C.; Wang, S. Molecular Reaction Mechanism for the Formation of 3-Chloropropanediol Esters in Oils and Fats. J. Agric. Food Chem. 2019, 67, 2700-2708. [CrossRef]

12. Merkle, S.; Ostermeyer, U.; Rohn, S.; Karl, H.; Fritsche, J. Mitigation strategies for ester bound 2-/3-MCPD and esterified glycidol in pre-fried breaded and frozen fish products. Food Chem. 2018, 245, 196-204. [CrossRef]

13. Wong, Y.H.; Lai, O.M.; Abas, F.; Nyam, K.L.; Nehdi, I.; Muhamad, H.; Tan, C.P. Factors Impacting the Formation of 3-MCPD Esters and Glycidyl Esters During Deep Fat Frying of Chicken Breast Meat. J. Am. Oil Chem. Soc. 2017, 94, 759-765. [CrossRef]

14. Wong, Y.H.; Muhamad, H.; Abas, F.; Lai, O.M.; Nyam, K.L.; Tan, C.P. Effects of temperature and $\mathrm{NaCl}$ on the formation of 3-MCPD esters and glycidyl esters in refined, bleached and deodorized palm olein during deep-fat frying of potato chips. Food Chem. 2017, 219, 126-130. [CrossRef]

15. MacMahon, S.; Begley, T.H.; Diachenko, G.W. Occurrence of 3-MCPD and glycidyl esters in edible oils in the United States. Food Addit. Contam. Part A 2013, 30, 2081-2092. [CrossRef]

16. Quan, W.; Li, Y.; Jiao, Y.; Xue, C.; Liu, G.; Wang, Z.; He, Z.; Qin, F.; Zeng, M.; Chen, J. Simultaneous generation of acrylamide, $\beta$-carboline heterocyclic amines and advanced glycation ends products in an aqueous Maillard reaction model system. Food Chem. 2020, 332, 127387. [CrossRef]

17. Zhang, Y.-Y.; Song, Y.; Hu, X.-S.; Liao, X.-J.; Ni, Y.-Y.; Li, Q.-H. Effects of sugars in batter formula and baking conditions on 5-hydroxymethylfurfural and furfural formation in sponge cake models. Food Res. Int. 2012, 49, 439-445. [CrossRef]

18. Parker, J.K.; Balagiannis, D.P.; Higley, J.; Smith, G.; Wedzicha, B.L.; Mottram, D.S. Kinetic Model for the Formation of Acrylamide during the Finish-Frying of Commercial French Fries. J. Agric. Food Chem. 2012, 60, 9321-9331. [CrossRef]

19. The State Food and Drug Administration. GB5009.168-2016 Determination of Fatty Acids in Foods; National Health and Family Planning Commission of China, and China Food and Drug Administration: Beijing, China, 2016.

20. National Health and Family Planning Commission. GB 5009.202-2016 Determination of Polar Components in Edible Oil; National Health and Family Planning Commission of China: Beijing, China, 2016.

21. Mogol, B.A.; Pye, C.; Anderson, W.; Crews, C.; Gökmen, V. Formation of Monochloropropane-1,2-diol and Its Esters in Biscuits during Baking. J. Agric. Food Chem. 2014, 62, 7297-7301. [CrossRef]

22. Ross, T. Indices for Performance Evaluation of Predictive Models in Food Microbiology. J. Appl. Bacteriol. 1996, 81, 501-508.

23. Crews, C.; Chiodini, A.; Granvogl, M.; Hamlet, C.; Hrncirik, K.; Kuhlmann, J.; Lampen, A.; Scholz, G.; Weisshaar, R.; Wenzl, T.; et al. Analytical approaches for MCPD esters and glycidyl esters in food and biological samples: A review and future perspectives. Food Addit. Contam. Part A 2013, 30, 11-45. [CrossRef]

24. Chaijan, M.; Panpipat, W. Pre-neutralized crude palm oil as natural colorant and bioactive ingredient in fish sausage prepared from tilapia (Oreochromis niloticus). LWT 2021, 135, 110289. [CrossRef]

25. European Food Safety Authority. Analysis of occurrence of 3-monochloropropane-1,2-diol (3-MCPD) in food in Europe in the years 2009-2011 and preliminary exposure assessment. EFSA J. 2013, 11, 3381. [CrossRef]

26. Givens, D.; Gibbs, R.; Rymer, C.; Brown, R. Effect of intensive vs. free range production on the fat and fatty acid composition of whole birds and edible portions of retail chickens in the UK. Food Chem. 2011, 127, 1549-1554. [CrossRef]

27. Li, C.; Li, L.; Jia, H.; Wang, Y.; Shen, M.; Nie, S.; Xie, M. Formation and reduction of 3-monochloropropane-1,2-diol esters in peanut oil during physical refining. Food Chem. 2015, 199, 605-611. [CrossRef]

28. Food, M.; Worldwide, C.; Hellmann, H.; Goyer, A. Antioxidants in Potatoes: A Functional View on One of the Major Food Crops Worldwide. Molecules 2021, 26, 2446.

29. Li, C.; Jia, H.; Shen, M.; Wang, Y.; Nie, S.; Chen, Y.; Zhou, Y.; Wang, Y.; Xie, M. Antioxidants Inhibit Formation of 3Monochloropropane-1,2-diol Esters in Model Reactions. J. Agric. Food Chem. 2015, 63, 9850-9854. [CrossRef]

30. Hammouda, I.B.; Zribi, A.; Mansour, A.B.; Matthäus, B.; Bouaziz, M. Effect of deep-frying on 3-MCPD esters and glycidyl esters contents and quality control of refined olive pomace oil blended with refined palm oil. Eur. Food Res. Technol. 2017, 243, 1219-1227. [CrossRef]

31. Mba, O.I.; Dumont, M.-J.; Ngadi, M. Deterioration Kinetics of Crude Palm Oil, Canola Oil and Blend During Repeated Deep-Fat Frying. J. Am. Oil Chem. Soc. 2016, 93, 1243-1253. [CrossRef]

32. Abdulkarim, S.; Long, K.; Lai, O.-M.; Muhammad, K.; Ghazali, H. Frying quality and stability of high-oleic Moringa oleifera seed oil in comparison with other vegetable oils. Food Chem. 2007, 105, 1382-1389. [CrossRef]

33. Zhou, H.; Jin, Q.; Wang, X.; Xu, X. Effects of temperature and water content on the formation of 3-chloropropane-1,2-diol fatty acid esters in palm oil under conditions simulating deep fat frying. Eur. Food Res. Technol. 2013, 238, 495-501. [CrossRef]

34. Aniołowska, M.; Kita, A. The Effect of Type of Oil and Degree of Degradation on Glycidyl Esters Content During the Frying of French Fries. J. Am. Oil Chem. Soc. 2015, 92, 1621-1631. [CrossRef]

35. Cheng, W.; Liu, G.; Guo, Z.; Chen, F.; Cheng, K.-W. Kinetic Study and Degradation Mechanism of Glycidyl Esters in both Palm Oil and Chemical Models during High-Temperature Heating. J. Agric. Food Chem. 2020, 68, 15319-15326. [CrossRef] [PubMed]

36. Ermacora, A.; Hrncirik, K. Study on the thermal degradation of 3-MCPD esters in model systems simulating deodorization of vegetable oils. Food Chem. 2014, 150, 158-163. [CrossRef]

37. Cheng, W.-W.; Liu, G.-Q.; Wang, L.-Q.; Liu, Z.-S. Glycidyl Fatty Acid Esters in Refined Edible Oils: A Review on Formation, Occurrence, Analysis, and Elimination Methods. Compr. Rev. Food Sci. Food Saf. 2017, 16, 263-281. [CrossRef]

38. Zelinkova, Z.; Svejkovska, B.; Velisek, J.; Dolezal, M. Fatty acid esters of 3-chloropropane-1,2-diol in edible oils. Food Addit. Contam. 2006, 23, 1290-1298. [CrossRef] [PubMed] 
39. Matthäus, B.; Pudel, F.; Fehling, P.; Vosmann, K.; Freudenstein, A. Strategies for the reduction of 3-MCPD esters and related compounds in vegetable oils. Eur. J. Lipid Sci. Technol. 2011, 113, 380-386. [CrossRef]

40. Pudel, F.; Benecke, P.; Fehling, P.; Freudenstein, A.; Matthäus, B.; Schwaf, A. On the necessity of edible oil refining and possible sources of 3-MCPD and glycidyl esters. Eur. J. Lipid Sci. Technol. 2011, 113, 368-373. [CrossRef]

41. Kimura, W.; Endo, Y. Decomposition products of glycidyl esters of fatty acids by heating. Biosci. Biotechnol. Biochem. 2017, 81, 581-586. [CrossRef] 